\title{
Electromagnetic Characteristics of a High Density Motor Drive System Using a Printed Power Circuit Board
}

\author{
Nobuyoshi Mutoh (Tokyo Metropolitan Institute of Technology) \\ Shinji Shirakawa, Kiyotugu Komatu, Naoto Ohnuma, and Sadao Hokari (Hitachi, Ltd.) \\ Fumio Harashima (Tokyo Metropolitan Institute of Technology)
}

\begin{abstract}
This paper describes a high-density motor drive system in which the power transmission lines are formed by a multi-layer printed board, making it possible to reduce inductance of lines. The structure of the power transmission lines between the converter and the inverter is determined, based on calculations of the magnetic field distribution generated by the differential (normal) mode current, which leads to an increase in radiated emissions due to the common mode current. The printed power circuit is experimentally verified as an effective way to reduce the electric field intensity from the radiation.
\end{abstract}

Key words: EMI, emissions, printed power circuit, differential mode current, common mode current.

\section{Introduction}

Recently, the switching speed of power devices such as IGBTs (Insulated Gate Bipolar Transistors) and microcomputers used in PWM motor drives has become higher and higher. As a result, PWM drives have the potential to cause electromagnetic interference (EMI) noise [1]. Some researchers have looked at EMI noise [2]-[4], but they mainly studied PWM inverters made using wire cables or a pair of bus bars formed of molded metal plates as the power transmission lines between the output of the converter and the input of the inverter. In the future, to avoid environmental pollution in the form of disposal after use, the control circuits should be made using a recyclable multi-layer printed power board.

So, the structure of a PWM inverter including a PWM converter using the multi-layer printed power board is studied. In the first half of section 2 , the source of radiated emissions is predicted through simulations, and in the second half the result is verified by measuring the magnetic fields radiated from a motor drive system. Section 3 uses these findings to analyze the structure of power transmission lines using a multi-layer power board which can better restrain radiated emissions. In the final section, the effects of the proposed method are shown through comparing the device electromagnetic characteristics with the multi-layer print type and the bus bar type power converter characteristics.

\section{EMI Noise Generated in Power Converters}

\subsection{Motor drive system}

EMI noise produced from a motor drive system (Fig.1) is studied. The motor drive system is comprised of a control board to perform PWM converter and PWM inverter control, and a power circuit board. The power circuit board has two kinds of three-phase power converters connected by power transmission lines, i.e. a PWM converter (or a diode rectifier) and a PWM inverter, gate drive circuits for driving these converters, a magnet switch, and a power supply (composed of AC/DC converter and DC/DC converter).

It is important for EMI problems to clarify the noise source. So, we begin with an examination through simulations, focusing on transient phenomena produced by switching operations of power converters because radiated emissions occur at higher frequencies.

\subsection{Prediction of the noise source}

Here, for the sake of simplicity, transient phenomena

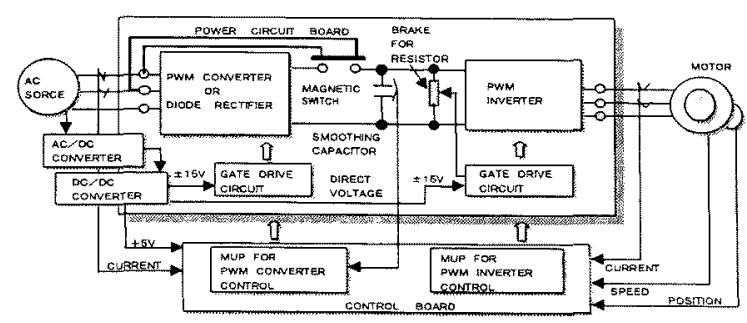

Fig. 1 Structure of motor drive system using a printed circuit board. 
are analyzed using the one-phase part in the three-phase power converter (inverter) which is shown by Fig.2 (a). The Pspice simulator (OrCAD) is used for this. The model is characterized by a resonance circuit formed by stray capacitance produced in the IPM, and PN line inductance (between the smoothing capacitor and $\mathrm{PN}$ terminal of (PM). The stray capacitor is compromised of a capacitor $\left(\mathrm{C}_{\text {agp }}\right)$ of $300 \mathrm{pF}$ (between the collector and gate), a capacitor $\left(\mathrm{C}_{\mathrm{gkp},}, \mathrm{C}_{\mathrm{gkn}}\right)$ of $3000 \mathrm{pF}$ (between the gate and emitter), a capacitor $\left(\mathrm{C}_{\text {cep }}, \mathrm{C}_{\mathrm{cen}}\right)$ of $2500 \mathrm{pF}$ (between collector and emitter) and a capacitor ( $C_{\text {akp }}$, $\mathrm{C}_{\mathrm{aknn}}$ ) of $1500 \mathrm{pF}$ (free-wheel diode). The PN line inductance is around $20 \mathrm{nH}$, and line inductance in the IPM is around 10nH.

Fig.2 (b) shows the simulated transient response waveform of the upper IGBT terminal voltage for the resonance circuit when the upper IGBT is turned off and the lower IGBT is turned on. The rising time $t_{r}$, fall time $t_{\text {uffi }}$ and dead time $t_{d}$ of the IGBTs used in the simulation are $0.2 \mu s, 0.2 \mu s$ and $0.1 \mu s$, respectively. Fig.2(c) shows the spectrum of harmonics components between 10 and $30 \mathrm{MHz}$ contained in the transient waveform shown by Fig.2 (b). The spectrum analysis has a peak around $15 \mathrm{MHz}$. On the other hand, the resonance frequency $f_{s}$ of the resonance circuit can be calculated by eq. (1), which is compromised of the stray capacitance and line inductance:

$$
f_{s}=\frac{1}{2 \pi \sqrt{L \times C}}
$$

where,

$$
\begin{aligned}
& \mathrm{L}=\mathrm{L}_{\mathrm{pn}}+\mathrm{L}_{\mathrm{p} 1}+\mathrm{L}_{\mathrm{p} 2}+\mathrm{L}_{\mathrm{n} 1}+\mathrm{L}_{\mathrm{n} 2} \\
& \mathrm{C}=\mathrm{C}_{\mathrm{agp}} \cdot \mathrm{C}_{\mathrm{gkp}} /\left(\mathrm{C}_{\mathrm{agp}}+\mathrm{C}_{\mathrm{gkp}}\right)+\mathrm{C}_{\text {cep }}+\mathrm{C}_{\mathrm{akp}} .
\end{aligned}
$$

In the above simulation, $\mathrm{L}$ and $\mathrm{C}$ are $30 \mathrm{nIF}$ and $4773 \mathrm{pF}$, respectively, and then $f_{s}$ is $14.1 \mathrm{MHz}$, which is near the spectrum analysis result shown in Fig.2(c). This means that the resonance circuit is formed every time the power devices repeat a turnoff, and fluctuations of the voltage around $15 \mathrm{MHz}$ are generated from this, leading to generation of the differential mode noise.

\subsection{Verification of the predicted noise source}

Fig. 3 shows experimental results of spectral analysis for output voltage of the PWM converter and input voltage of the PWM inverter. The harmonic component around $16.8 \mathrm{MHz}$ appears and this frequency is near the

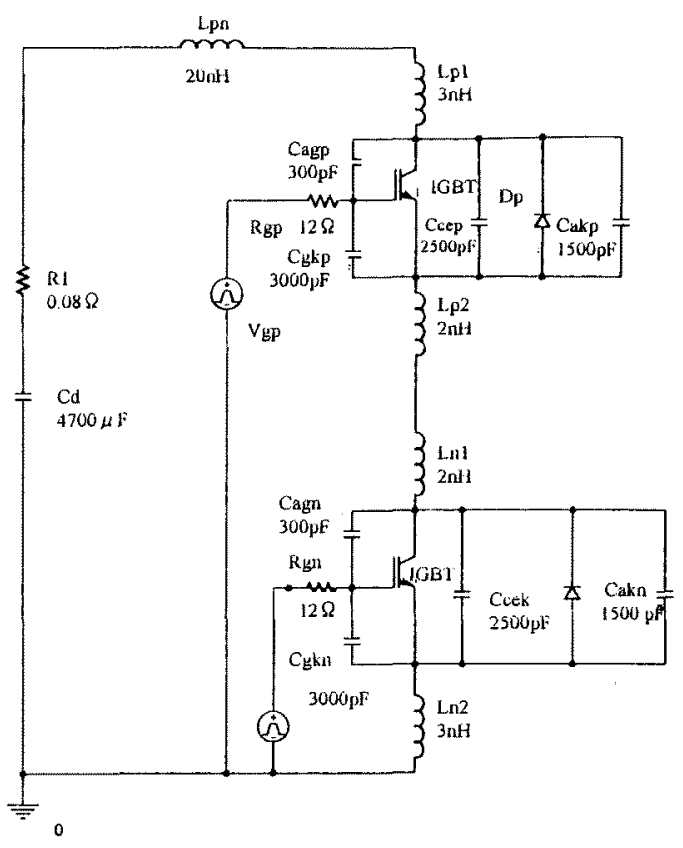

(a) Resonance circuit formed in an arm of a power converter.

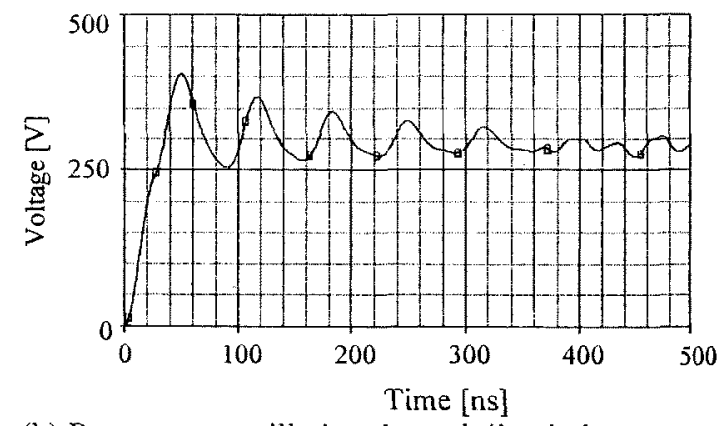

(b) Resonance oscillation through line inductance and stray capacitor.

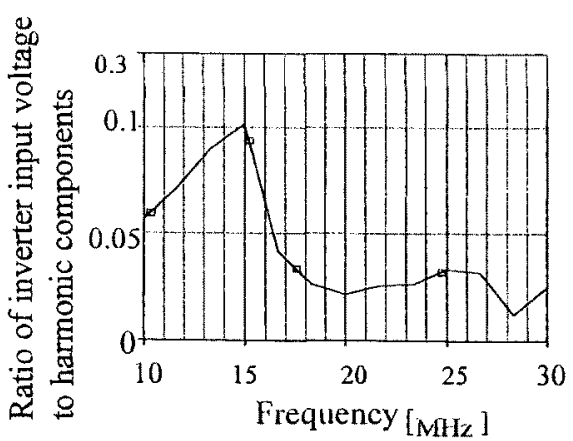

(c) Spectrum of harmonics components appearing between 10 and $30 \mathrm{MHz}$.

Fig.2 Calculated frequency spectrum of the harmonic components generated from a resonance circuit. 
one obtained by the simulation.

Fig. 4 shows conduction EMI noise for the harmonic components around $15 \mathrm{MHz}$, which is generated from only the PWM inverter, and from both PWM converter and PWM inverter are transmitted to the $\mathrm{AC}$ source side shown in Fig.1 via power transmission lines connecting to these power converters. It is found from these data that in both cases, noise generated around $15 \mathrm{MHz}$ is transmitted to the power source side through the power transmission lines. Therefore, it is supposed that the noise is transferred together with the normal mode current flowing on the power transmission lines as differential (normal) mode noise. This can be verified by experimental results shown in Fig.5, which shows magnetic fields with the same frequency as that of the noise appear above the converter, above the power transmission lines between the converter and the inverter, and above the inverter that are paths of normal mode currents.

\subsection{Noise having an effect on radiated emissions}

A. Experimental investigations

As there are various kinds of stray capacitors in the motor drive system [3], it is supposed that common mode current flows through capacitors in the resonance circuit due to variations of transient voltage that occur when power devices are driven. So, to examine this fact, the motor drive system shown by Fig. 1 has been made using a printed power board. Fig. 6 shows the power converter structure used. Two converters (IPMs) are connected by power transmission lines using pairs of molded metal plates. The power transmission lines between the converter and the inverter have a parallel plate structure with inserted dielectric so as not to increase line inductance.

Fig.7 (a) shows the measured magnetic field distribution at $16.8 \mathrm{MHz}$ corresponding to the frequency giving the maximum in Fig.5. The magnetic field appears to surround the $\mathrm{P}$ - and $\mathrm{N}$-power transmission lines between the converter and the inverter, according to the structure shown in Fig.6. This means that the currents of the same direction, i.e. common mode currents, flow on the upper (connected $\mathrm{P}$ terminal) and lower (connected $\mathrm{N}$ terminal) power transmission lines and they influence the radiated emissions. Then, the common mode currents, which flow on the upper and lower power transmission lines in the same direction, are concluded to generate the radiated emissions (EMI noise)

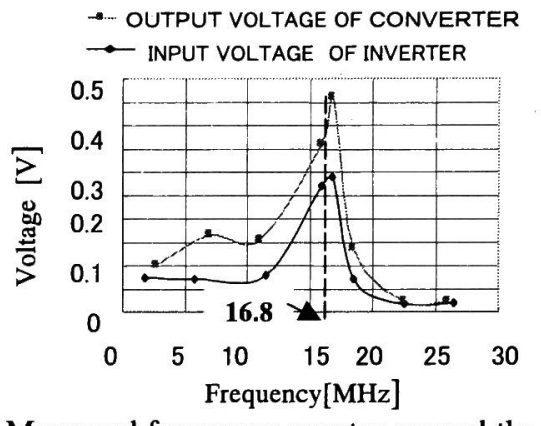

Fig.3 Measured frequency spectra around the $15 \mathrm{MHz}$ of harmonics components which appear in the converter output and inverter input.

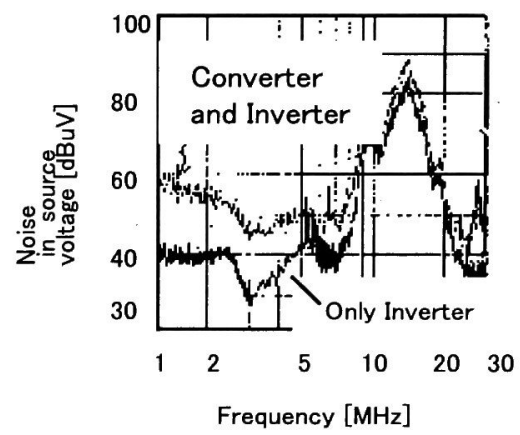

Fig. 4 Noise around $15 \mathrm{MHz}$ transmitted to source side from the converter and inverter.

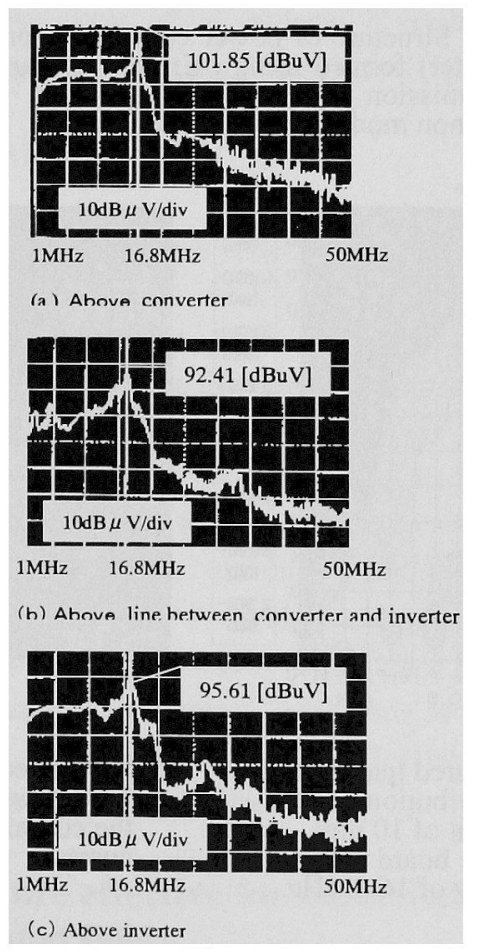

Fig.5 Magnetic fields when the height of the magnetic field probe is $15 \mathrm{~mm}$. 
of the motor drive system.

B. Verification by analysis

The conclusion cited above is theoretically verified by calculating the magnetic field distribution generated by the common mode currents using the moment method. In the calculation, input and output terminals of the upper and lower power transmission lines between the converter and the inverter are electrically shorted, and the terminal of the smoothing capacitor is also shorted as the impedance of the smoothing capacitor is recognized

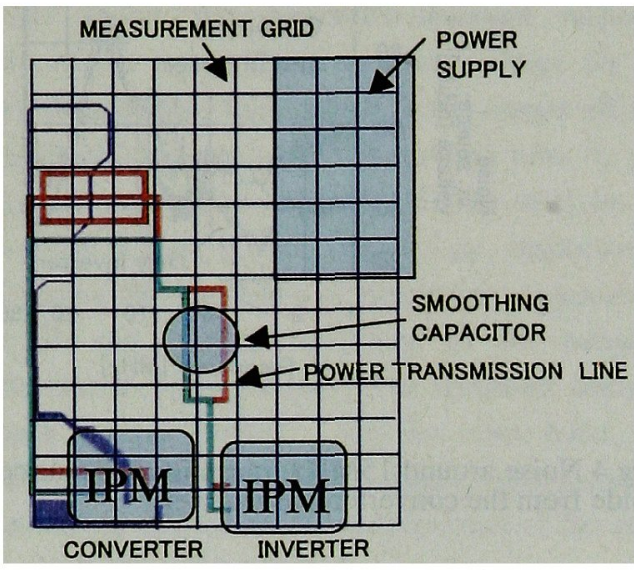

Fig.6 Structure of power converter (converter and inverter) formed using pairs of bus bars as power transmission lines to demonstrate effects of common mode currents on emission.
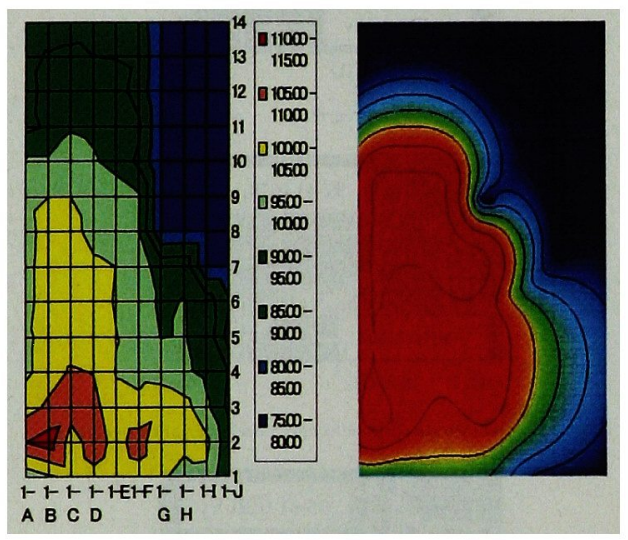

(a) Measured magnetic field distribution at a height of $10 \mathrm{~mm}$ above the board and frequency of $16.8 \mathrm{MHz}$.

(b) Calculated magnetic field generated by the common mode current.

Fig.7 Magnetic field distributions generated by the common mode current flowing power in the circuit board.

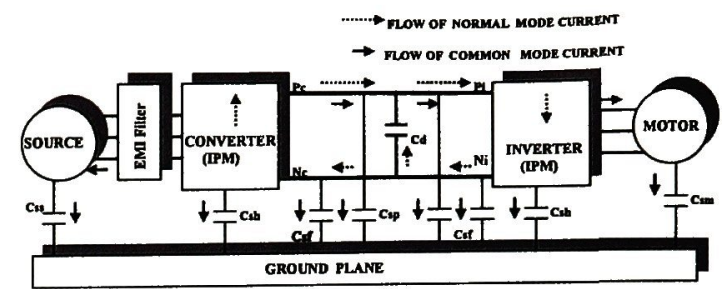

Fig. 8 Normal mode current supplying electric power to a motor, and paths of common mode currents flowing through stray capacitors formed on the power circuit.

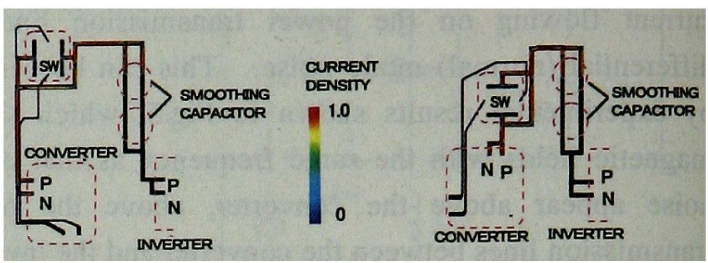

(a-1) Power circuit A

(a-2) Power Circuit B

(a) Current distribution produced on power transmission lines.
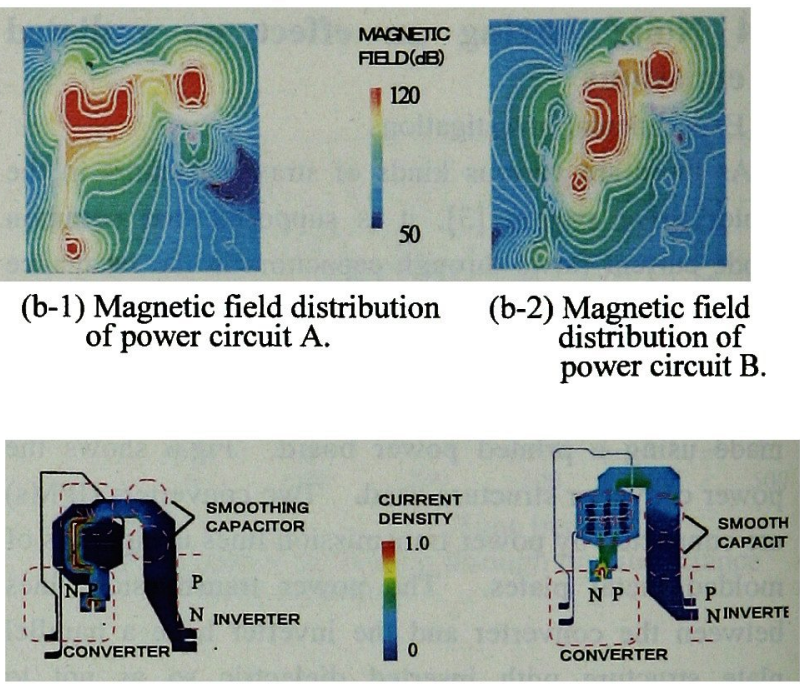

(c-1) Power circuit C.

(c-2) Power circuit D.

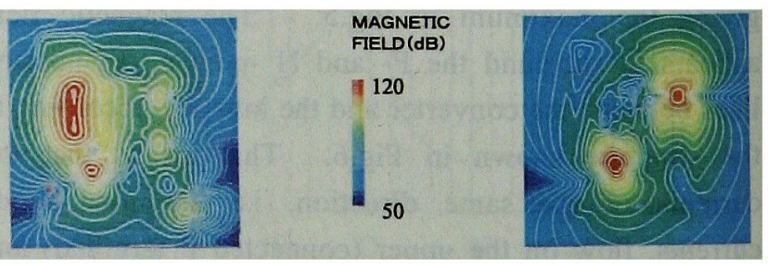

(d-1) Magnetic field distribution of power circuit $\mathrm{C}$.

(d-2) Magnetic field distribution of power circuit $\mathrm{D}$.

Fig.9 Calculated results of the current distribution and the magnetic field, for various kinds of power line transmission structures to reduce differential mode noise. 
as zero in the considered high frequency regions. A unit voltage is applied between the two terminals of the power transmission lines so that the same current, i.e. the common mode currents can flow on the upper and lower power transmission lines.

In calculation of the magnetic field distribution, the weight function $\vec{w}$ using the method described in reference [4] is introduced to satisfy eq. (4) for each element on the divided surface of the power transmission lines.

$$
\int_{s} \vec{w} \cdot \vec{E} d S=0
$$

The relationship between the surface currents on the transmission lines and the incident electric field is given by eqs. (5) and (6):

$$
\vec{J}_{c}\left(\vec{r}^{\prime}\right)=\sum_{i=1}^{N} \vec{w}_{i} \cdot I_{i}
$$

where $N$ is the number of unknown quantities, and

$$
\begin{aligned}
& j \omega \sum_{i=1}^{N}\left\{\frac{\mu_{0}}{4 \pi} \int_{S_{j}} \int_{S_{i}} \vec{w}_{j} \vec{w}_{i} d S_{i} d S_{j}\right\} \times I_{i}+ \\
& \frac{1}{j \omega} \sum_{i=1}^{N}\left\{\frac{-1}{4 \pi \varepsilon_{0}} \int_{S_{l}} \int_{S_{i}}\left(\nabla \cdot \vec{w}_{j}\right) \cdot\left(\nabla \cdot \bar{w}_{i}\right) p d S_{i} d S_{j}\right\} \times I_{i} \\
& =\int_{S_{j}} \vec{w}_{j} \cdot \vec{E}_{0} d S_{j} .
\end{aligned}
$$

Here, the coefficient $j \omega$, coefficient $1 / j \omega$ and the right side of the equation are expressed inductance, reciprocal of stray capacitance and voltage source generated from the power converter, respectively. Eq. (6) is rewritten as eq. (7).

$$
\left\lfloor Z_{i j}\right] \cdot\left[I_{i}\right]=[V i]
$$

Unknown current $[I i]$ can be obtained if the source voltage vector $\left[V_{i}\right]$ is given, and the impedance matrix $\left\lfloor z_{i j}\right\rfloor$ corresponding to the structure of the power transmission lines is determined. If the voltage source $V i$ is normalized as $1 \mathrm{~V}$, the magnetic field $\vec{H}(\vec{r})$ is given by eq. (8) using $I i$ obtained from eq. (7).

$$
\vec{H}(\vec{r})=\sum_{i=1}^{N} I_{i}\left\{-\frac{1}{4 \pi} \int_{S_{i}} \vec{w} \times \nabla \varphi d S_{i}\right\}+\vec{H}_{0}
$$

Here, $\vec{H}_{0}$ is incident magnetic field, and it is set as zero.

Fig.7 (b) shows calculated the magnetic field distribution produced by the common mode current using the above method. Comparison of each magnetic field distribution shows that the radiated emissions are generated due to the common currents as the calculated magnetic field distribution agrees with the measured distribution of the power transmission lines. As shown by current flows of Fig.8, harmonic noise produced by switching operations of the power devices is transferred on power transmission lines together with differential mode currents. Finally, their currents are shunted into paths made by various kinds of stray capacitors as common mode currents. These loops of the common mode currents produced in the drive system result in the increase in radiated emissions.

It was concluded from the above discussion that the source of the radiated emissions was the differential mode currents. So, a structure of the power transmission lines is studied in the next section, which can reduce the magnetic field distribution produced by the differential mode currents.

\section{Structure of Power Transmission Lines}

\subsection{Analyzing structure}

The radiated electric field, intensity $E$ generated by the differential mode current is generally given by eq. (9) [5]:

$$
E=2.64 \times 10^{-14} S^{2} / d
$$

where $S$ is loop area of the differential mode current $I ; f$, frequency of the current; $d$, distance from the radiation source. As only the area $S$ can be designed, the length between the output terminal of the converter and the input terminal of the inverter, i.e. distance between Pand $\mathrm{N}$ - terminals must be shortened until the permissible value of isolation. So, the power transmission lines are made as a symmetric structure sandwiched by a dielectric between the $\mathrm{P}$ - and N-terminals. In the structure, the differential mode voltage $V_{d f}\left(=L_{e f} d i / d t\right)$ can be reduced as the mutual inductance $M$ between Pand $\mathrm{N}$ - lines is produced so that the effective inductance line $L_{e f}\left(=L_{p}+L_{n}-2 M\right)$ decreases.

\subsection{Structure effective for reduction in radiated fields}

Fig.9 shows the current density and the magnetic field distribution for various kinds of power transmission line 
structures. The analysis is done using differential mode currents that flow on the transmission lines by shorting electrically the terminal of the smoothing capacitor and the inverter, and by applying unit voltage $1 \mathrm{~V}$ of the frequency $10 \mathrm{MHz}$ between $\mathrm{P}$ - and $\mathrm{N}$ - terminals of the converter side. Power circuits A (size: $335 \mathrm{~mm} \times$ $441 \mathrm{~mm}$ ) and $B$ (size: $370 \mathrm{~mm} \times 420 \mathrm{~mm}$ ) are made using $\mathrm{P}$ - and $\mathrm{N}$ - molded metal plates (width: $6 \mathrm{~mm}$, thickness: $1.5 \mathrm{~mm}$ ) between which a dielectric is inserted. Structural differences between power circuits $A$ and $B$ are found from Figs.9 (a-1) and (a-2); the total transmission line length of power circuit $B$ is shorter than that of power circuit $A$, and the laminated area of power transmission lines in power circuit $B$ is less than that of power circuit $A$. These structural differences result in the line inductance calculated using eqs. (6) and (7) for A being $385.6 \mathrm{nH}$, which is larger than the value $(348.8 \mathrm{nH})$ of $B$. This means that the method to laminate power transmission lines can effectively reduce the line inductance in comparison with the method to shorten them.

Moreover, analyzed results shown by Figs. 9(b-1) and (b-2) indicate that a strong magnetic field is produced on the non-laminated area such as the magnet switch or the smoothing capacitor. So, structure of the power transmission lines using a multi-layer-printed board is studied, which can easily make the laminated structure. The multi-layer-printed board studied has a 4-layer structure; first layer, gate circuits, source supply lines; second layer, P-power transmission line; third layer, $\mathrm{N}$-power transmission line, and fourth layer, ground plane.

Figs. 9(c-1) and 9(c-2) show only the structure of the $\mathrm{P}$-and $\mathrm{N}$-power transmission lines. In these cases, the lines can be widened in comparison with the molded metal type structure shown in Figs. 9 (a-1) and 9 (a-2), and the distance between $\mathrm{P}$ - and $\mathrm{N}$ - power transmission lines is reduced to $0.4 \mathrm{~mm}$ from $1.6 \mathrm{~mm}$.

Fig. 9(c-1) shows the structure (power circuit C) laminating the power transmission line area near the smoothing capacitor where the strong magnetic field is produced. In this case, the line inductance between the converter and the smoothing capacitor can be decreased to $69.1 \mathrm{nH}$ from $287.1 \mathrm{nH}$, which is the same as power circuit $\mathrm{B}$.

In power circuit $\mathrm{D}$, the area of the magnet switch is also laminated, for which a strong magnetic field appears in Fig.9 (c-1). As a result, in the final circuit D, the total line inductance and the magnetic field produced could be reduced to $1 / 9$ and $1 / 10$ of the values obtained in the initial designed circuit $A$, respectively. So, the power circuit $\mathrm{D}$ is expected to reduce effectively radiated emissions.

\section{Experimental Results}

Fig.10 shows electric field intensity measured under the condition that the distance between the power converter and the antenna is $3 \mathrm{~m}$. A $2.2 \mathrm{~kW}$ induction motor is driven by the power converter with the power transmission line structure cited above. As shown by Fig.10, regardless of the antenna direction, in the power circuit $\mathrm{D}$ using the multi-layer printed board the electric field intensity is reduced more than $10 \mathrm{~dB}$ at comparatively low radiated emission frequencies between $30 \mathrm{MHz}$ and $150 \mathrm{MHz}$ (FM radio frequency band). As the common mode current $I_{c}$ is generally given in eq.(10)[5], the influence of common mode currents is strong in low radiated emission regions.

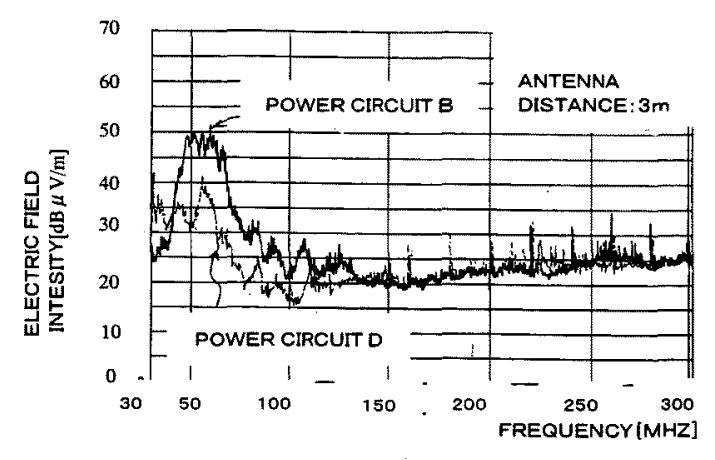

(a) When the direction of the antenna is horizontal.

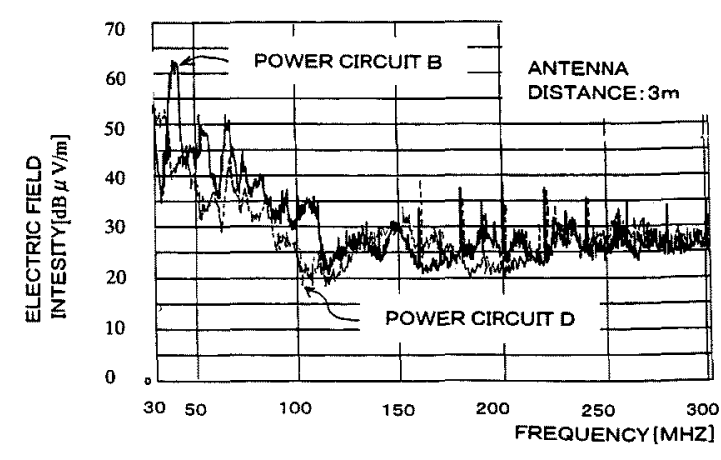

(b) When the direction of the antenna is vertical. Fig.10 Effects of structural differences of power transmission lines on radiated emissions of motor drive systems. 
$E=4 \pi \times 10^{-7} \cdot I_{c} \cdot f \cdot l / d$

This is because the common mode currents are a function of the first power of the frequency, while the differential mode currents are a function of the second power of the frequency, as expressed by eq. (9).

As shown in Fig.11 (a) (areas of A and B), the less the radiated frequency is decreased, the more common mode currents have an effect on emissions. That is to say, earthing by a wire cable (wiring earth) increases radiated emissions in comparison with the surface earth (Fig.11 (b)), which is connected to the ground. This is because the ground inductance $L_{G}$ is reduced by the surface earth and then the common mode voltage $V_{G}\left(=2 \pi L_{G} I_{C} f\right)$ can be decreased. The ground plane of the power circuit D acts to reduce common mode voltage $V_{G}$.

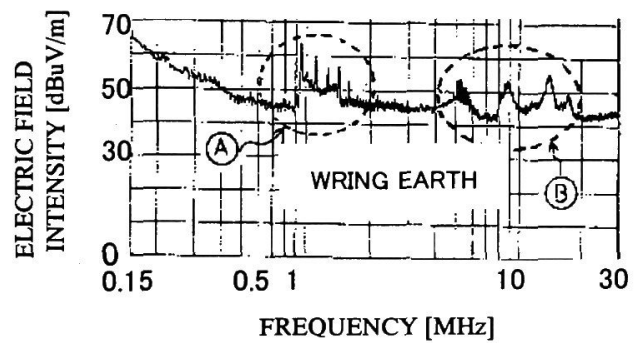

(a)When the frame is connected with the earth through a cable wire.

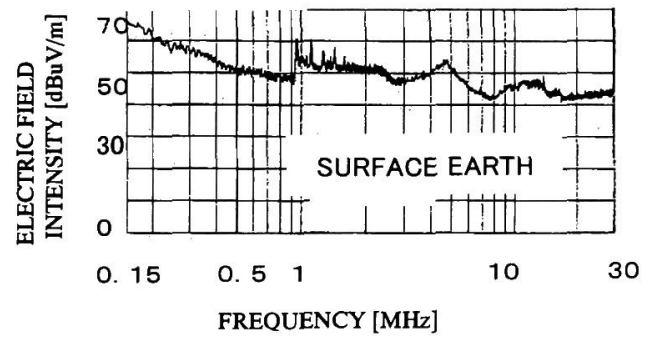

(b) When the surface of the frame is connected with the earth.

Fig.11 Effects of ground connection method on radiated emissions.

\section{Conclusions}

The power transmission lines used in the power converters were studied to reduce EMI noise (radiated emissions) by using a printed circuit board in the converters.

1) The magnetic field produced by the differential mode current was weakened by decreasing the distance between $\mathrm{P}$ - and $\mathrm{N}$-lines and shortening their length within permissible ranges.

2) It was effective to reduce line inductance by laminating elements (smoothing capacitor, etc.) arranged between the converter and the inverter. This decreased the magnetic field.

3) Making a surface earth using the printed circuit with a ground layer (ground plane) reduced the common mode voltage as the ground inductance could be reduced.

(Manuscript received January 26, 2000, revised July 31, 2000)

\section{References}

[1] G. L. Skibinki, R. J. Kerkman, and D. Schelegel, "EMI Emissions of Modern PWM AC Drives," IEEE Industry Applications Magazine, Nov./Dec. pp.47-81, 1999

[2] R. Scheich, J. Roudet, "EMI Conducted Emission in the Differential Mode Emanating from an SCR: Phenomena and Noise Level Prediction," IEEE Trans. on PELS, Vol. 10, No.2, pp.105- 110, Mar., 1995

[3] G. Grandi, D. Casadei, U. Reggiani, “ Analysis of Common-and Differential-Mode HF Current Components in PWM Inverter-Fed AC Motors," IEEE PELS conference Vol.2, pp. 1146-1151, May 1998

[4] S. Shirakawa, N. Mutoh, K. Komatu, " Using Computer Simulation to Analyze Electromagnetic Emissions Generated in PWM Inverter," Trans. IEE Japan, Vol.119-D, No.2, pp.195-203, 1999

[5] C. R. Paul, "Introduction to Electromagnetic Compatibility, " Chap. 8.1.3, 1992

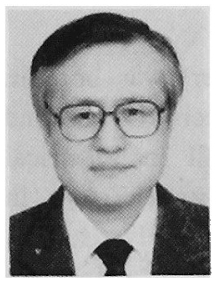

Nobuyoshi Mutoh (Member) was born on April 1, 1948. In March 1975, he completed the first half of his Doctor's course in the Science and Engineering Research Division of the Graduate School of Waseda University. He joined Hitachi Research Laboratory of Hitachi, Ltd. in April of that year.

From February 1995 to February 1998, he was a Senior Engineer in the Elevator Development Center, Mito Works. From February 1998 to March 2000, He was a Senior 
Researcher in the Second Department of Power Electronics Research, Hitachi Research Laboratory. He is currently a Professor in the Department of Electronic Systems Engineering, Tokyo Metropolitan Institute of Technology. He received an OHM Technology Award in 1989 and a Kanto District Invention Award in 1994. He has a Doctor of Engineering degree, and is a Registered Professional Engineer. $\mathrm{He}$ is an IEEE Senior Member.

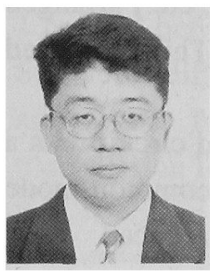

Shinji Shirakawa (Member) was born on April 23, 1964 in Hokkaido, Japan. $\mathrm{He}$ received the Master of Engineering degree in electronic engineering from Hokkaido University, Japan, in 1989. He previously worked on electromagnetic wave simulation in the Energy Research Laboratory, Hitachi

Ltd. He is now a researcher with Hitachi Research Laboratory, Hitachi Ltd., where he is concerned with the packaging design for power electronic converters.

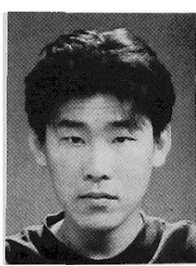

Naoto Ohnuma (Member) was born in Niigata Prefecture, Japan, on August 17, 1970. He graduated from Niigata Technical High School, Niigata, Japan, in 1989. In 1989, he joined Hitachi, Ltd., Hitachi Research Laboratory. He has been developing elevator drive control systems at Hitachi, Ltd., Elevators \& Escalators Division.

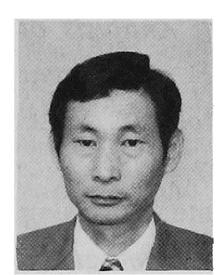

Sadao Hokari (Member) was born in Niigata Prefecture, Japan, on July 19, 1952. He graduated from Niigata East Technical High School, Niigata, Japan, in 1971. He then joined Hitachi, Ltd., Hitachi Research Laboratory. He has been developing elevator drive control systems at Hitachi, Ltd.,

Elevators \& Escalators Division.

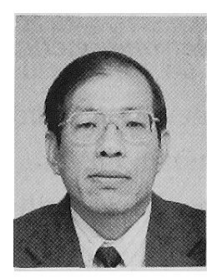

Kiyotugu Komatu (Non-member) was born in Yamanashi Prefecture, Japan, in July 1949. He graduated from Kofu Technical High School, Kofu, Japan, in 1968. He then joined Hitachi, Ltd., Hitachi Research Laboratory. He has been developing the packaging design for elevator drive systems at

Hitachi, Ltd., Mito Works.

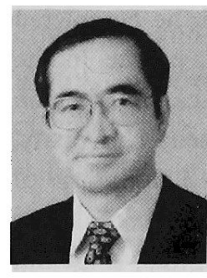

Fumio Harashima (Member) was born in Tokyo in 1940 . He has received B.S., and M.S. and Ph.D. degrees all in Electrical Engineering from University of Tokyo in 1962, 1964 and 1967, respectively. He was employed as Associate Professor at Institute of Indusial Science, University of Tokyo in 1967, and had been Professor from 1980 through 1998. He was Director of the Institute from 1992 to 1995. In 1996-1998, he joined Kagawa University as adjunct professor for establishing new faculty of engineering. The Faculty of Engineering, Kagawa University, opened in April 1998. He has been President of Tokyo Metropolitan Institute of Technology since April 1998. His research interests are in power electronics, mechatronics and robotics. $\mathrm{He}$ is a co-author of four books and has published over 1,000 technical papers in these areas. He has been active in various academic societies such as Institute of Electrical Engineers of Japan, Instrument and Control Engineers of Japan (SICE), Robotics Society of Japan and IEEE. He has served as President of IEEE Industrial Electronics Society in 1986-1987 and 1990 IEEE Secretary. He was also a member of IEEE N\&A Committee in 1991-1992, and IEEE Fellow Committee in 1991-1993. He served as Editor-in-Chief of IEEE/ASME Transactions on Mechatronics in 1995. Dr. Harashima has received a number of awards including 1978 SICE Best Paper Award, 1983 IEE of Japan Best Paper Award, 1984 IEEE/IES Anthony J. Hornfeck Award and 1988 IEEE/IES Eugene Mittelmann Award. He is a Fellow in IEEE and SICE. Dr. Fumio Harashima is Professor Emeritus of University of Tokyo. 